\title{
Styracaceae endémicas del Perú
}

\section{Blanca León ${ }^{1,2}$}

${ }^{1}$ Museo de Historia Natural, Av. Arenales 1256, Aptdo. 14-0434, Lima 14, Perú

2 Plant Resources Center, University of Texas at Austin, Austin TX 78712 EE.UU.

blanca.leon@mail.utexas.edu

\section{Resumen}

La familia Styracaceae es reconocida en el Perú por presentar dos géneros y 20 especies (Brako \& Zarucchi, 1993; Ulloa Ulloa et al., 2004), principalmente árboles y arbustos. En este trabajo reconocemos tres especies endémicas en el género Styrax. Estos endemismos se encuentran en la región Bosques Muy Húmedos Montanos, entre los 2200 y $2800 \mathrm{~m}$ de altitud. Estos taxones se encuentran representados dentro del Sistema Nacional de Áreas Naturales Protegidas por el Estado.

Palabras claves: Styracaceae, Styrax, Perú, endemismo, plantas endémicas.

\section{Abstract}

The Styracaceae are represented in Peru by two genera and approximately 20 species (Brako \& Zarucchi, 1993; Ulloa Ulloa et al., 2004), mostly shrubs and trees. Here we recognize three endemic species in the genus Styrax. Endemic species are found in Very Humid Montane Forests region, between 2200 and 2800 m elevation. These endemic species have been recorded within Peru's protected areas system.

Keywords: Styracaceae, Styrax, Peru, endemism, endemic plants.

\section{Styrax nunnezii P.W. Fritsch}

\section{DD}

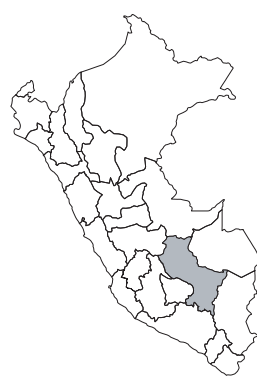

Publicación: Novon 14(1): 50, f. 3. 2004. Colección tipo: P. Núñez et al. 23320 Herbarios: AAU, BR, CAS, COL, F, GH, K, LOJA, LPB, MICH, MO, NY, TEX, US, W.

Nombre común: Desconocido.

Registro departamental: CU.

Regiones Ecológicas: BMHM; $2445 \mathrm{~m}$. SINANPE: PNO

Herbarios peruanos: Ninguno.

Observaciones: Árbol de hasta $6 \mathrm{~m}$ de alto, conocido de una población, ubicada en el suroriente del país, de la cuenca del Apurímac. Esta especie podría ser coespecífica con Styrax vilcabambae, la cual fue descrita de la misma cuenca.

\section{Styrax omuk B. Walln.}

\section{EN, B1a}

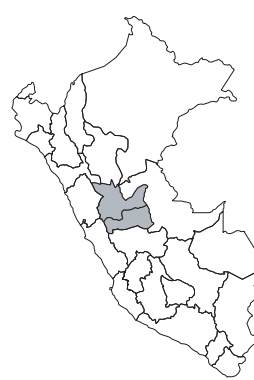

Publicación: Ann. Naturhist. Mus. Wien, Ser. B, Bot. Zool. 99: 712. 1997.

Colección tipo: B. Wallnöfer 19-30488

Herbarios: G, K, LZ, NY, W.

Nombre común: Desconocido.

Registro departamental: HU, PA.

Regiones Ecológicas: BMHM; 2200$2500 \mathrm{~m}$.

SINANPE: PNYC, RCS

Herbarios peruanos: USM (1).

Observaciones: Especie arbórea conocida de unas pocas localidades, en el centro del país, en las cuencas del Pachitea y Chontabamba. Al parecer, está restringida a las cimas de cordilleras aisladas, por tanto, sus poblaciones se hallan naturalmente fragmentadas. Fue descrita de una planta recolectada en la cima de la Cordillera del Sira, localidad hoy en el Reserva Comunal El Sira.

\section{Styrax vilcabambae (D.R. Simpson) B. Walln.}

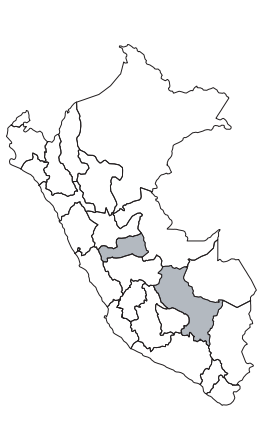

\section{VU, B1ab(iii)}

Publicación: Ann. Naturhist. Mus. Wien, Ser. B, Bot. Zool. 99: 681—720. 1997. Colección tipo: T.R. Dudley 10808

Herbarios: MO, NA; USM!.

Nombre común: Desconocido.

Registro departamental: CU, PA.

Regiones Ecológicas: BMHM; 2240$2800 \mathrm{~m}$.

SINANPE: PNO, PNYC

Herbarios peruanos: HUT (1), USM (isotipo+2).

Observaciones: Esta especie arbórea, de $2-7 \mathrm{~m}$ de alto, fue descrita de una planta recolectada de la cuenca del Apurímac, en la Cordillera de Vilcabamba, al sur del Parque Nacional Otishi. Esta especie parece tener afinidad con Styrax nunneziii. Poblaciones adicionales han sido registradas en el Parque Nacional YancahagaChemillén. 